\title{
Graphite Nanoplatelets in Elastomer Composites
}

\author{
I.A. Estrada-Moreno $^{1 *}$, C. Leyva-Porras ${ }^{2}$, M.E. Mendoza-Duarte ${ }^{2}$, S.G. Flores Gallardo ${ }^{2}$, J.L. Rivera- \\ Armenta $^{3}$ \\ 1. CONACyT - Centro de Investigación en Materiales Avanzados, S.C. (CIMAV), Chihuahua, México. \\ 2. Ingeniería y Química de Materiales, Centro de Investigación en Materiales Avanzados, S.C., \\ Chihuahua, México. \\ 3. Centro de Investigación en Petroquímica Secundaria. Instituto Tecnológico de Ciudad Madero, \\ Altamira, México. \\ * Corresponding author: ivan.estrada@cimav.edu.mx
}

Graphite and graphene in elastomers composites have shown to improve electrical conductivity, mechanical properties and gas barrier properties of the matrix [1-2]. Among different fabrication methods, melt compounding is the most important for compounding elastomer composites, due to its simplicity and low cost. Also, this method imparts high shear stresses to the mixture, stimulating a possible exfoliation of the graphite. In this study, expanded graphite (EG) was used to prepare elastomer composites. The role of mixing conditions (i.e., temperature, and speed of mixing) in the evolution of EG to graphite nanoplatelets $(\mathrm{GnP})$ were investigated by electron microscopy, X-ray diffraction, and electrical conductivity measurements.

SEBS was used as the polymer matrix and EG as reinforcing filler. The composites were prepared by melt-compounding in an internal mixer (Brabender PLASTI-CORDER). The samples were obtained by compression molding. The composites were analyzed using an X-ray diffractometer (Xpert MPD Phillips), with an X-ray wavelength of $0.154 \mathrm{~nm}$. The dynamic mechanical analysis (DMA) measurements were performed in a RSA III (TA Instruments) DMA employing a Dual Cantilever geometry at a fixed frequency $(1 \mathrm{~Hz})$ and $25^{\circ} \mathrm{C}$.

The initial morphology of EG is portrayed in Figure 1a. As noted, EG particles exhibit a micrometric dimension. The graphite flake did not show any exfoliation as it looks opaque due to layer stacking. The $\mathrm{X}$-ray diffraction pattern of EG is shown in Figure 1b. As observed, the well-known sharp reflection around $2 \theta=26.4^{\circ}$, corresponding to the interlayer spacing $\mathrm{d}=0.34 \mathrm{~nm}$, is present [3]. Also, Figure $1 \mathrm{~b}$ plots patterns of graphite particles obtained from composites at different mixing temperatures, A (235 ${ }^{\circ} \mathrm{C}$ ) and $\mathrm{B}\left(190{ }^{\circ} \mathrm{C}\right)$, at same EG concentration. As the peak intensity is proportional to the absolute crystalline content, the intensity variation observed indicates that EG particles in composites processed at $\mathrm{B}$ condition present greater delamination than EG particles in composites processed at A condition.

Figure 2 illustrates graphite particles obtained by solvent dilution from A and B composites. Particle thickness was reduced as compared against pristine EG particles. This delamination is attributed to the shear stress experimented by the EG particles during the melt compounding. Figure $2 \mathrm{~b}$ portraits the obtained GnP; as noted, transparency reflects lower thickness. This phenomenon is remarked due to the SEBS higher viscosity in B than in A composite. X-Ray and TEM images suggest that the initial EG particle thickness is reduced, evolving from an EG into GnP. 


\section{References:}

[1] Y Shao et al., Electroanalysis 22 (2010), p. 1027.

[2] I Estrada et al., Macromol. Symp. 283 (2009), p. 361.

[3] H Kim, C Macosko, Polymer 50 (2009), p. 3797.

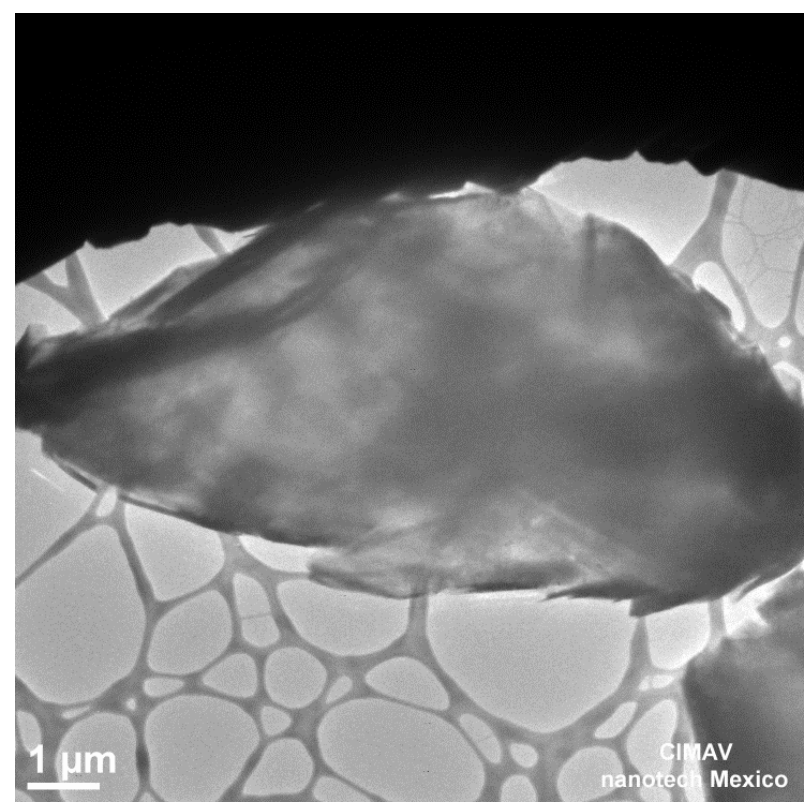

a)

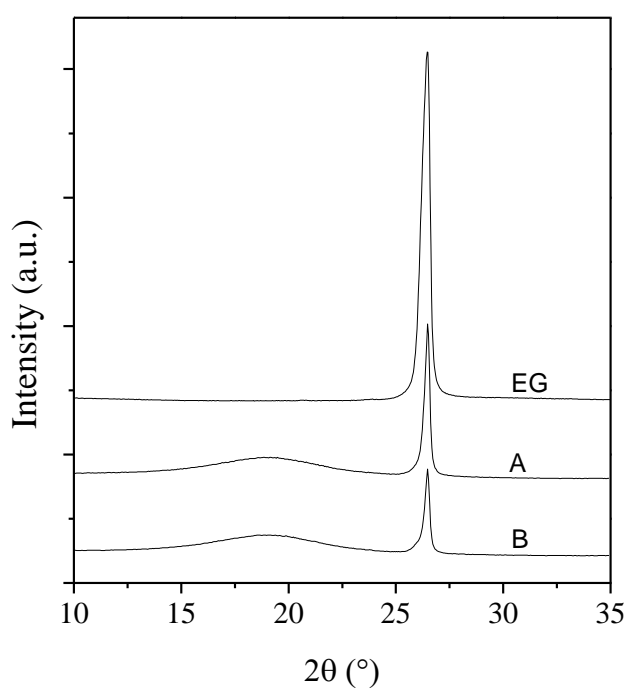

b)

Figure 1. a) TEM micrograph of EG particle, and b) X-ray diffraction patterns of EG, composite (SEBS/EG) A and B at $6 \mathrm{wt} \%$ EG.

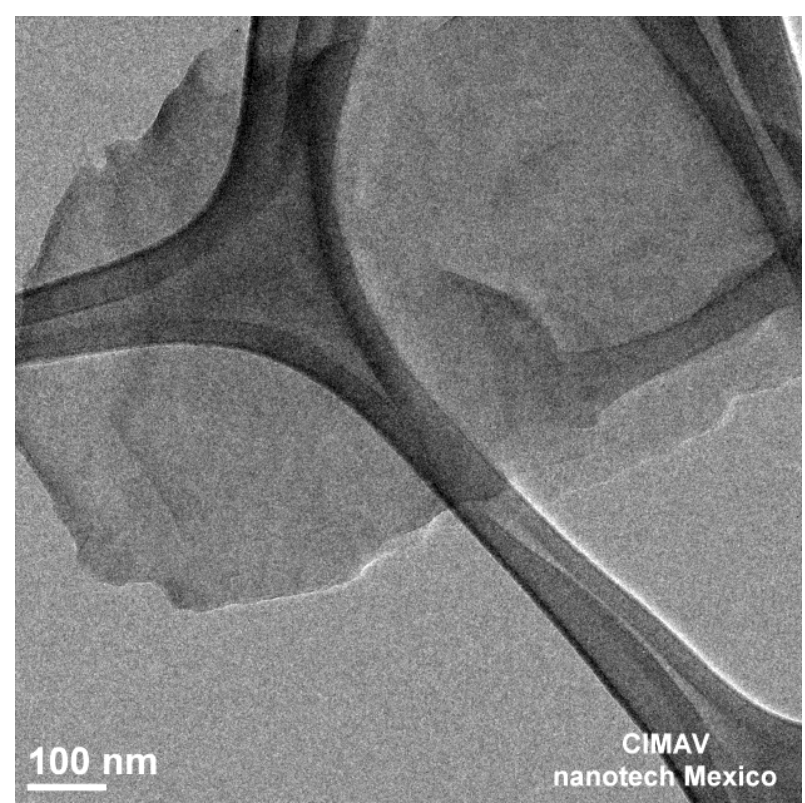

a)

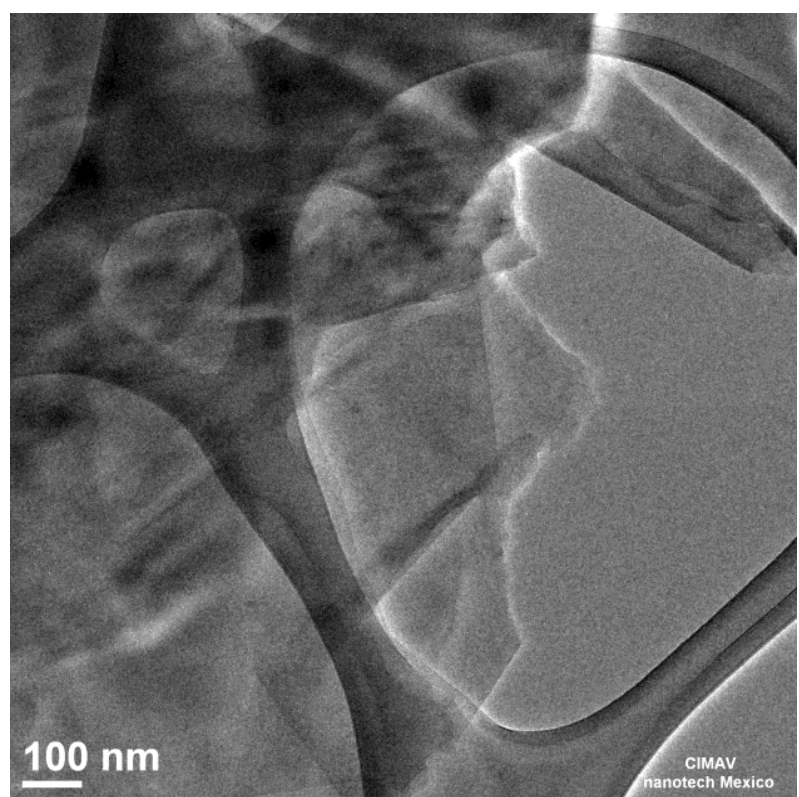

b)

Figure 2. TEM micrographs of EG particle obtained from a composite of a) A condition $\left(235^{\circ} \mathrm{C}\right)$, and b) B condition $\left(190^{\circ} \mathrm{C}\right)$. 